\title{
On exchange rates and economic growth
}

\author{
Eric O'N. Fisher \\ Department of Economics, The Ohio State University, 410 Arps Hall, 1945 North High Street, \\ Columbus, $\mathrm{OH} 43210$, USA
}

\begin{abstract}
Extending Ireland's (1994) model, this paper analyzes an international economy where cash or credit can be used for payment. Foreign trade credit is more costly than its domestic analog. A depreciation of the real exchange rate is associated with an external surplus and a reduced share of imports purchased with credit. Economic growth slows when foreign trade credit becomes the predominant means of payment for international transactions. A country with high inflation exports its Tobin effect and thus temporarily increases world growth.
\end{abstract}

\section{Introduction}

Extending Ireland's (1994) elegant model, this paper explores how exchange rates and trade credits affect international economic growth. Building on the work of Prescott (1987) and Schreft (1992), Ireland explores the margin between cash and credit goods. In any market, consumers may pay cash or buy on credit. Each good is characterized by how closely integrated its market is into the local financial system, and goods are ordered by their fixed credit costs. Since the opportunity cost of buying with cash is forgone interest, consumers typically use credit in markets where it is inexpensive.

An immediate question is: what is a credit good? Lucas and Stokey (1987) argue that leisure, a non-market good, is a typical example. This interpretation is strictly correct but slightly unsatisfactory for international economists, since the crux of our sub-discipline hangs upon the gains from trade (of presumably marketed goods). I propose the following explanation. The cash-in-advance 
constraint is really a description of an explicit lag in the payments mechanism, as Kohn (1981) has emphasized. These delays are characteristic of international commerce, and most trade is accomplished through letters of credit between major commercial banks and concomitant bank transfers. ${ }^{1}$ Thus international credit goods are those for which the payment lags are longer than the typical holding period for foreign exchange.

This way of thinking about credit goods has a felicitous byproduct for an international economist. An unpleasant implication of simple cash-in-advance models in international economics is that the exogenous payments mechanism typically implies unit velocities for both domestic and foreign currency. ${ }^{2}$ In the analysis below, these velocities are determined endogenously, and domestic currency has a higher velocity than foreign exchange during the early stages of growth.

Of course, exchange rates are endogenous asset prices in a full description of the world economy. Thus it is not appropriate to think that a real depreciation 'causes' export-led growth or that higher rates of money creation 'lead to' a weaker nominal exchange rate. Instead, it is better to emphasize that exchange rates are inextricably linked with monetary policies, inflation rates, and nominal interest rates in equilibrium. In a classic paper, Helpman (1981) shows that exchange rates, interest rates, and the supplies of high-powered money are not independent. Indeed, in the economies described below, if central banks target nominal interest rates, then there is a continuum of equilibria parameterized by the initial nominal exchange rate. $^{3}$ Since nominal interest rates determine inflation profiles, each such exchange rate corresponds to a different money supply process in every country. These policies then determine trade balances, investment, and thus world growth.

Money is not neutral because Ireland's model has an explicit Tobin (1965) effect. The model has a very simple supply side, and higher inflation corresponds to higher nominal rates. These in turn raise the shadow value of holding money, and a wider range of goods is bought on credit. But financial intermediation uses real resources and thus affects growth. For most plausible specifications of the costs of credit, these growth effects are transitory, but Ireland's model establishes a transparent link between inflation and growth. It fleshes out Tobin's

\footnotetext{
${ }^{1}$ That some of these off-balance-sheet activities provide tax advantages and circumvent reserve requirements is not immaterial.

${ }^{2}$ The international reserves of the U.S. monetary authority in 1994 were about $\$ 74$ billion and total imports were near $\$ 818$ billion, implying a velocity near 11 . In the same year, the stock of domestic currency was $\$ 355$ billion and GDP was $\$ 6931$ billion, entailing a velocity of about 18 .

${ }^{3}$ The analysis in Dupour (1997) suggests that this result may be a general property of cash-inadvance models in international economics.
} 
intuition: higher inflation spurs capital accumulation, even as it lowers society's welfare. In an international economy, higher foreign inflation raises world growth, even as it lowers welfare in every country.

Much of the analysis hinges upon the costs of credit. I adopt a simple specification, and credit for a foreigner is more expensive than it is for a local. Countries will typically buy a range of domestic goods on credit well before they begin to use foreign financial intermediaries. Indeed, a country usually experiences three stages of growth. First, its domestic financial system develops, as local residents buy a wider range of domestic goods on credit. Second, it experiences a decrease in growth as it becomes integrated into the world financial system and imports the services of foreign financial intermediaries. Third, it grows at a rate reflecting a combination of society's discount factor and the marginal efficiency of investment. In the long run, the share of resources used in domestic and foreign financial intermediation may become negligible.

The rest of this paper is structured as follows. The next section will present the model. Section 3 will discuss properties of the equilibrium, and Section 4 will present simulations of the model for a world consisting of two large countries whose underlying growth rate is near that of the United States in recent decades. Section 5 draws some brief conclusions and suggests directions for future research.

\section{The model}

The model is an extension of Ireland's (1994), and thus its exposition will be cursory, except when the details of the international economy bear elucidation. There is a continuum of domestic goods and another continuum of foreign goods. Each good is distinguished by its location, and goods differ by how much it costs to purchase them on credit. Thus a good's location is its distance, in terms of the ease of intermediation, from a country's financial center, and credit costs increase with distance. There are two countries, and the costs of obtaining domestic and foreign credit are different. The cost of credit in any market, at home or abroad, is a recurring fixed cost that an agent pays to a local financial intermediary. Once the cost is paid, an agent can purchase as much as he wishes of that good on credit in that period.

Agents can opt to buy domestic goods with cash or imports with foreign exchange. Of course, the opportunity cost of buying a good with cash is the interest forgone. Since the cost of credit increases away from the financial center, there may be a fringe of domestic cash goods. Likewise, a country will accumulate foreign exchange if the costs of foreign credit are high.

Let $X_{t}$ be the set of measurable functions whose typical element is $x_{t}:\{H, F\} \times[0,1] \rightarrow \mathfrak{R}_{+}$, and write $X=\prod_{t=1}^{\infty} X_{t}$. Then $U: X \rightarrow \mathfrak{R}$ is the social 
welfare function for the domestic economy; its rule is

$$
U(c)=\sum_{t=1}^{\infty} \beta^{t-1} \int_{0}^{1}\left[u\left(c_{\mathrm{H} t}(i)\right)+u\left(c_{\mathrm{FF}}(i)\right)\right] \mathrm{d} i
$$

where $c_{\mathrm{Ht}}(i)$ represents the consumption of the $i$ th home good at time $t, c_{\mathrm{Ft}}(i)$ is analogous, and $c=\left(\left(c_{\mathrm{H} t}(i)\right)_{i \in[0,1]},\left(c_{\mathrm{Ft}}(i)\right)_{i \in[0,1}\right)_{t=1}^{\infty}$ is the entire consumption profile for the domestic economy. The assumption that preferences are separable in domestic and foreign goods is no stronger than the analogous postulate for goods in different locations.

The foreign consumption profile is $c^{*}=\left(\left(c_{\mathrm{H} t}^{*}(i)\right)_{i \in[0,1]},\left(c_{\mathrm{Ft}}^{*}(i)\right)_{i \in[0,1]}\right)_{t=1}^{\infty},{ }^{4}$ and the analogous social welfare function is $U^{*}\left(c^{*}\right)$. The foreign and domestic economies discount future felicity at the same rate; this assumption is unavoidable since country-specific discount factors give rise to degenerate long-run distributions of wealth. ${ }^{5}$ Still, countries' felicity functions may differ, and the gains from trade can be very large if these functions satisfy the usual Inada conditions, since an economy cannot produce its trading partner's goods.

Producers of domestic goods are uniformly distributed along the unit interval, and foreign firms are likewise distributed along a different unit interval. Production in the domestic economy is given by

$$
y_{t}(i)=A k_{t}(i)
$$

where $y_{t}(i)$ the output of the $i$ th good and $k_{t}(i)$ is capital per worker in that sector, both at time $t$. Assume that $A \beta>1$ so that growth is possible. ${ }^{6}$ Production in the foreign economy is described by $y_{t}^{*}(i)=A k_{t}^{*}(i)$. Thus the marginal product of capital is identical in all sectors in both countries, and the physical location of the capital stock is indeterminate. These functions are perhaps unduly simple, but our focus is on the relationship between monetary policy, financial intermediation, and economic growth, and it is appropriate to keep production as simple as possible. Since goods are produced by identical technologies, all domestic goods sell for $p_{\mathrm{H} t}$ and all foreign goods sell for $p_{\mathrm{F} t}$ in a competitive equilibrium. Finally, the notation $k_{t}=\int_{0}^{1} k_{t}(i) \mathrm{d} i$ and $k_{t}^{*}=\int_{0}^{1} k_{t}^{*}(i) \mathrm{d} i$ will be convenient below.

Now I can give a formal description of the technology for financial intermediation. The cost of domestic credit, in units of the $i$-th domestic good, is described by a strictly increasing and differentiable function $\gamma_{\mathrm{H}}(i)$, with $\gamma_{\mathrm{H}}(0)=0$. The cost of foreign trade credit, denominated in units of a foreign good, is described by an

\footnotetext{
${ }^{4}$ The convention is that the subscript $\mathrm{H}$ or $\mathrm{F}$ refers to a location and an asterisk refers to the foreign household.
}

${ }^{5}$ See Becker (1980) for an elegant discussion.

${ }^{6}$ See Jones and Manuelli (1997). 
analogous $\gamma_{\mathrm{F}}(i)$. I impose that $\gamma_{\mathrm{F}}(0)>0$ since it is more difficult for a foreign intermediary to verify the financial status of a domestic agent, even in the foreign financial center. Thus the full cost of purchasing $c_{\mathrm{H} t}(i)$ units of a domestic credit good is $p_{\mathrm{H} t}\left(c_{\mathrm{H} t}(i)+\gamma_{\mathrm{H}}(i)\right)$ and that of purchasing a foreign good using trade credit is $p_{\mathrm{Ft}}\left(c_{\mathrm{Ft}}(i)+\gamma_{\mathrm{F}}(i)\right)$. The foreign country faces analogous costs $\gamma_{\mathrm{H}}^{*}(\cdot)$ and $\gamma_{\mathrm{F}}^{*}(\cdot)$, where the former is the cost to foreigners of obtaining credit in our home market and the latter is their cost of credit in their own country.

Each economy faces two cash-in-advance constraints, one for home goods and another for foreign goods. The sequence of events is as follows. In period 0 , a household splits its initial assets between domestic currency, foreign currency, domestic bonds, and foreign bonds. At this time the nominal exchange rate is $e_{0}$, the gross interest rate on bonds denominated in domestic currency is $R_{\mathrm{HO}}$, and that on foreign bonds is $R_{\mathrm{Fo}}$. During period 1, each household goes shopping, constrained by its available cash balances in both denominations. Also, it uses income from production, investment income, and its moneys held in excess of shopping needs to buy a portfolio for period 2. During period 1, a household buys foreign exchange at the nominal rate of $e_{1}$ per unit of domestic currency, and it buys bonds at the discount factors $R_{\mathrm{H} 1}$ and $R_{\mathrm{F} 1}$. Thus the opportunity cost of money of either denomination is the forgone interest on the relevant period 0 bond. This process then repeats itself.

The domestic household faces the constraint:

$$
H_{0} \geqslant M_{\mathrm{H} 1}+B_{\mathrm{H} 1} / R_{\mathrm{H} 0}+e_{0}\left(M_{\mathrm{F} 1}+B_{\mathrm{F} 1} / \mathrm{R}_{\mathrm{F} 0}\right),
$$

where $H_{0}$ are initial lump-sump transfers of high-powered money from the domestic government, $M_{\mathrm{H} 1}$ is money balances chosen at time 0 for shopping at time $1, B_{\mathrm{H} 1}$ are domestic bonds maturing at time $1, e_{0}$ is the price of foreign exchange, and the other variables are analogous. For $t=1,2, \ldots$, the domestic household faces the constraints:

$$
\begin{aligned}
& \left(M_{\mathrm{H} t}+B_{\mathrm{H} t}+H_{t}\right) / p_{\mathrm{H} t}+e_{t}\left(M_{\mathrm{F} t}+B_{\mathrm{Ft}}\right) / p_{\mathrm{H} t}+A k_{t} \\
& \geq k_{t+1}+\int_{0}^{1} c_{\mathrm{H} t}(i) \mathrm{d} i+\int_{0}^{1} \chi_{\mathrm{H} t}(i) \gamma_{\mathrm{H}}(i) \mathrm{d} i+M_{\mathrm{H} t+1} / p_{\mathrm{H} t} \\
& \quad+B_{\mathrm{H} t+1} / R_{\mathrm{H} t} p_{\mathrm{H} t}+\left(e_{t} p_{\mathrm{F} t} / p_{\mathrm{H} t}\right)\left(\int_{0}^{1} c_{\mathrm{Ft}}(i) \mathrm{d} i+\int_{0}^{1} \chi_{\mathrm{F} t}(i) \gamma_{\mathrm{F}}(i) \mathrm{d} i\right) \\
& \quad+\left(e_{t} / p_{\mathrm{H} t}\right)\left(M_{\mathrm{F} t+1}+B_{\mathrm{F} t+1} / R_{\mathrm{F} t}\right), \\
& M_{\mathrm{H} t} / p_{\mathrm{H} t} \geq \int_{0}^{1}\left[1-\chi_{\mathrm{H} t}(i)\right] c_{\mathrm{H} t}(i) \mathrm{d} i, \\
& M_{\mathrm{Ft} t} / p_{\mathrm{F} t} \geq \int_{0}^{1}\left[1-\chi_{\mathrm{Ft}}(i)\right] c_{\mathrm{Ft}}(i) \mathrm{d} i
\end{aligned}
$$


where $\chi_{\mathrm{H} t}(i)$ takes the value of unity if domestic good $i$ is purchased with credit at time $t$ and is zero otherwise. The indicator function $\chi_{\mathrm{F} t}(i)$ is analogous. Notice that the household is constrained by the costs of domestic and foreign credit. Also, investment is the quintessential credit good since it requires no cash in advance and its fixed credit cost is zero. Further, the domestic economy faces $k_{t+1} \geq 0, M_{\mathrm{H} t} \geq 0$ and $M_{\mathrm{Ft}} \geq 0$.

Here are the foreign country's constraints:

$$
H_{0}^{*} \geq\left(M_{\mathrm{H} 1}^{*}+B_{\mathrm{H} 1} / R_{\mathrm{H} 0}\right) / e_{0}+\left(M_{\mathrm{F} 1}+B_{\mathrm{F} 1} / R_{\mathrm{F} 0}\right)
$$

and for $t=1,2, \ldots$,

$$
\begin{aligned}
& \left(M_{\mathrm{H} t}^{*}+B_{\mathrm{H} t}^{*}+H_{t}^{*}\right) / e_{t} p_{\mathrm{F} t}+\left(M_{\mathrm{F} t}^{*}+B_{\mathrm{F} t}^{*}\right) / p_{\mathrm{F} t}+A k_{t}^{*} \\
& \geq k_{t+1}^{*}+\left(p_{\mathrm{H} t} / e_{t} p_{\mathrm{F} t}\right)\left(\int_{0}^{1} c_{\mathrm{H} t}^{*}(i) \mathrm{d} i+\int_{0}^{1} \chi_{\mathrm{H} t}^{*}(i) \gamma_{\mathrm{H}}^{*}(i) \mathrm{d} i\right) \\
& \quad+\left(M_{\mathrm{H} t+1}^{*}+B_{\mathrm{H} t+1}^{*} / R_{\mathrm{H} t}\right) / e_{t} p_{\mathrm{F} t}+\int_{0}^{1} c_{\mathrm{F} t}^{*}(i) \mathrm{d} i+\int_{0}^{1} \chi_{\mathrm{F} t}^{*}(i) \gamma_{\mathrm{F}}^{*}(i) \mathrm{d} i \\
& \quad+M_{\mathrm{F} t+1}^{*} / p_{\mathrm{F} t}+B_{\mathrm{F} t+1}^{*} / p_{\mathrm{F} t} R_{\mathrm{F} t}, \\
& M_{\mathrm{H} t}^{*} / p_{\mathrm{H} t} \geq \int_{0}^{1}\left[1-\chi_{\mathrm{H} t}^{*}(i)\right] c_{\mathrm{H} t}^{*}(i) \mathrm{d} i \\
& M_{\mathrm{F} t}^{*} / p_{\mathrm{F} t} \geq \int_{0}^{1}\left[1-\chi_{\mathrm{F} t}^{*}(i)\right] c_{\mathrm{F} t}^{*}(i) \mathrm{d} i
\end{aligned}
$$

where all the variables and the indicator functions $\chi_{\mathrm{H} t}^{*}(i)$ and $\chi_{\mathrm{F} t}^{*}(i)$ are analogous. Likewise, $k_{t+1}^{*} \geq 0, M_{\mathrm{H} t}^{*} \geq 0$, and $M_{\mathrm{F} t}^{*}(i) \geq 0$ must also hold.

Material balances are given by:

$$
\begin{aligned}
& k_{t+1}+\int_{0}^{1}\left[c_{\mathrm{H} t}(i)+c_{\mathrm{H} t}^{*}(i)\right] \mathrm{d} i+\int_{0}^{1}\left[\chi_{\mathrm{H} t}(i) \gamma_{\mathrm{H}}(i)+\chi_{\mathrm{H} t}^{*}(i) \gamma_{\mathrm{H}}^{*}(i)\right] \mathrm{d} i \leq A k_{t}, \\
& k_{t+1}^{*}+\int_{0}^{1}\left[c_{\mathrm{F} t}(i)+c_{\mathrm{F} t}^{*}(i)\right] \mathrm{d} i+\int_{0}^{1}\left[\chi_{\mathrm{F} t}(i) \gamma_{\mathrm{F}}(i)+\chi_{\mathrm{F} t}^{*}(i) \gamma_{\mathrm{F}}^{*}(i)\right] \mathrm{d} i \leqslant A k_{t}^{*} .
\end{aligned}
$$

The equilibrium conditions in the currency markets are:

$$
\begin{aligned}
& M_{\mathrm{H} t+1}+M_{\mathrm{H} t+1}^{*} \leq \sum_{\mathrm{k}=0}^{t} \mathrm{H}_{k} \\
& M_{\mathrm{F} t+1}+M_{\mathrm{F} t+1}^{*} \leq \sum_{k=0}^{t} \mathrm{H}_{k}^{*} .
\end{aligned}
$$


Equilibrium in the two bond markets is described by

$$
\begin{aligned}
& B_{\mathrm{H} t+1}+B_{\mathrm{H} t+1}^{*}=0, \\
& B_{\mathrm{F} t+1}+B_{\mathrm{F} t+1}^{*}=0 .
\end{aligned}
$$

Let $\delta_{\mathrm{H} 0}=\delta_{\mathrm{F} 0}=1, \delta_{\mathrm{H} t}=\prod_{s=1}^{t}\left(1 / R_{\mathrm{H} s-1}\right)$, and $\delta_{\mathrm{F} t}=\prod_{s=1}^{t}\left(1 / R_{\mathrm{Fs}-1}\right)$ be the nominal discount factors for home and foreign bonds respectively. Then the asset markets also satisfy

$$
\lim _{t \rightarrow \infty} \delta_{\mathrm{H} t} B_{\mathrm{H} t}=\lim _{t \rightarrow \infty} \delta_{\mathrm{F} t} B_{\mathrm{F} t}=\lim _{t \rightarrow \infty} \delta_{\mathrm{H} t} B_{\mathrm{H} t}^{*}=\lim _{t \rightarrow \infty} \delta_{\mathrm{F} t} B_{\mathrm{F} t}^{*}=0 .
$$

An equilibrium is a list of consumption plans $\left(c, c^{*}\right)$, money holdings $\left\{\left(M_{\mathrm{H} t}, M_{\mathrm{F} t}\right),\left(M_{\mathrm{H} t}^{*}, M_{\mathrm{F} t}^{*}\right)\right\}_{t=1}^{\infty}$, bond holdings $\left\{\left(B_{\mathrm{H} t}, B_{\mathrm{F} t}\right),\left(B_{\mathrm{H} t}^{*}, B_{\mathrm{F} t}^{*}\right)\right\}_{t=1}^{\infty}$, investment plans $\left\{k_{t+1}, k_{t+1}^{*}\right\}_{t=1}^{\infty}$, corresponding good prices $\left\{\left(p_{\mathrm{H} t}, p_{\mathrm{F} t}\right)\right\}_{t=1}^{\infty}$, assets prices $\left\{\left(R_{\mathrm{H} t}, R_{\mathrm{F} t}, e_{t}\right)_{t=0}^{\infty}\right.$, such that each economy maximizes its own welfare, taking prices, the initial distribution of real wealth $\left(k_{1}, k_{1}^{*}\right)$, and lump-sum transfers of high powered money $\left\{\left(H_{t}, H_{t}^{*}\right)\right\}_{t=0}^{\infty}$ as given. Of course, consumption, investment, and portfolio choices must satisfy material balances and the asset market conditions as well.

\section{Some properties of equilibrium}

Let $\lambda_{t}, \mu_{\mathrm{H} t}$, and $\mu_{\mathrm{F} t}$ be the shadow values of Eqs. (2)-(4) respectively, and define $\rho_{t} \equiv e_{t} p_{\mathrm{F} t} / p_{\mathrm{H} t}$, the real exchange rate at time $t$. The domestic country's maximization problem entails that $u^{\prime}\left(c_{\mathrm{H} t}(i)\right)=\lambda_{t}$ if domestic good $i$ is purchased with credit and $u^{\prime}\left(c_{\mathrm{H} t}(i)\right)=\lambda_{t}+\mu_{\mathrm{H} t}$ if it is purchased with home currency. Also, $u^{\prime}\left(c_{\mathrm{Ft}}(i)\right)=\rho_{t} \lambda_{t}$ if foreign good $i$ is purchased with foreign credit and $u^{\prime}\left(c_{\mathrm{Ft}}(i)\right)=\rho_{t} \lambda_{t}+\mu_{\mathrm{Ft}}$ if it is purchased with foreign exchange. Let the shadow values of Eqs. $\left(2^{*}\right)-\left(4^{*}\right)$ have the obvious notation. The analogous conditions for the foreign country in its own market are $u^{* \prime}\left(c_{\mathrm{Ft} t}^{*}(i)\right)=\lambda_{t}^{*}$ and $u^{*^{\prime}}\left(c_{\mathrm{F} t}^{*}(i)\right)=\lambda_{t}^{*}+\mu_{\mathrm{F} t}^{*}$. Likewise, $u^{*^{\prime}}\left(c_{\mathrm{H} t}^{*}(i)\right)=\lambda_{t}^{*} / \rho_{t}$ and $u^{*^{\prime}}\left(c_{\mathrm{H} t}^{*}(i)\right)=\lambda_{t}^{*} / \rho_{t}+\mu_{\mathrm{H} t}^{*}$ obtain for foreign imports of credit and cash goods, respectively.

Let $\tilde{c}_{\mathrm{H} t}=\left(u^{\prime}\right)^{-1}\left(\lambda_{t}\right)$ be the amount of a credit good purchased, and let $\hat{c}_{\mathrm{H} t}=\left(u^{\prime}\right)^{-1}\left(\lambda_{t}+\mu_{\mathrm{H} t}\right)$ be that of domestic cash good purchased. Assume that the felicity functions are increasing concave functions that satisfy the usual Inada conditions. Then $\tilde{c}_{\mathrm{H} t} \geq \hat{c}_{\mathrm{H} t}>0$, with strict inequality when the cash in advance constraint binds. Thus the decision to purchase home goods on credit is summarized by:

$$
\chi_{\mathrm{H} t}(i)= \begin{cases}1 & \text { if } u\left(\tilde{c}_{\mathrm{H} t}\right)-\lambda_{t}\left(\tilde{c}_{\mathrm{H} t}+\gamma_{\mathrm{H}}(i)\right) \geq u\left(\hat{c}_{\mathrm{H} t}\right)-\left(\lambda_{t}+\mu_{\mathrm{H} t}\right) \hat{c}_{\mathrm{H} t}, \\ 0 & \text { otherwise. }\end{cases}
$$

The shadow value of the cash-in-advance constraint satisfies $\mu_{\mathrm{H} t}>0$ when the domestic interest rate is strictly positive. Hence an important aspect of this rule 
is that no credit good would be purchased if the domestic nominal interest rate were zero. Also, when this rate is high, a wider selection of domestic credit goods is bought.

Let $\tilde{c}_{\mathrm{F} t}=\left(u^{\prime}\right)^{-1}\left(\lambda_{t} \rho_{t}\right)$ and $\hat{c}_{\mathrm{F} t}=\left(u^{\prime}\right)^{-1}\left(\lambda_{t} \rho_{t}+\mu_{\mathrm{F} t}\right)$. A depreciation of the real exchange rate lowers the quantities of both credit and cash goods imported. Thus a real depreciation has the usual affect on the trade balance by decreasing the volume of all imports. The rule for determining imports bought with credit and foreign exchange is

$$
\chi_{\mathrm{F} t}(i)= \begin{cases}1 & \text { if } u\left(\tilde{c}_{\mathrm{F} t}\right)-\lambda_{t} \rho_{t}\left(\tilde{c}_{\mathrm{F} t}+\gamma_{\mathrm{F}}(i)\right) \geq u\left(\hat{c}_{\mathrm{F} t}\right)-\left(\lambda_{t} \rho_{t}+\mu_{\mathrm{F} t}\right) \hat{c}_{\mathrm{F} t}, \\ 0 & \text { otherwise. }\end{cases}
$$

Recall that the costs of foreign financial intermediation are strictly greater than zero. Thus during the early stages of economic growth, no imports are bought on credit if $\lambda_{t} \rho_{t} \gamma_{\mathrm{F}}(0)>\mu_{\mathrm{F} t} \hat{c}_{\mathrm{F} t}$ and the fixed costs of foreign financial intermediation exceed the interest forgone on foreign exchange holdings. As the domestic economy grows, a range of imports is eventually bought on credit if the foreign interest rate is strictly positive.

Let $\tilde{c}_{\mathrm{F} t}^{*}=\left(u^{* \prime}\right)^{-1}\left(\lambda_{t}^{*}\right)$ and $\hat{c}_{\mathrm{F} t}^{*}=\left(u^{* \prime}\right)^{-1}\left(\lambda_{t}^{*}+\mu_{\mathrm{F} t}^{*}\right)$. Again, the properties of the felicity functions imply that $\tilde{c}_{\mathrm{F} t}^{*} \geq \hat{c}_{\mathrm{F} t}^{*}>0$. Let $\tilde{c}_{\mathrm{H} t}^{*}=\left(u^{*^{\prime}}\right)^{-1}\left(\lambda_{t}^{*} / \rho_{t}\right)$ and $\hat{c}_{\mathrm{H} t}^{*}=\left(u^{* \prime}\right)^{-1}\left(\lambda_{t}^{*} / \rho_{t}+\mu_{\mathrm{F} t}^{*}\right)$. Now a real depreciation increases the quantities of both credit and cash goods exported to foreigners. Since the felicity functions are fairly general, domestic and foreign goods may not be perfect substitutes, and the absolute version of purchasing power parity typically will not hold. Still, the rules $\chi_{\mathrm{F} t}^{*}(i)$ and $\chi_{\mathrm{H} t}^{*}(i)$ are simple, but the latter now involves the term $\lambda_{t}^{*} / \rho_{t}$. The real exchange rate has a clear function in this model. It plays a role that is exactly analogous to the shadow value of Eq. (2) or Eq. $(2 *)$ as it pertains to international transactions. Hence a depreciation of the real exchange rate affects cross-border trade exactly as does a rise in $\lambda_{t}$ and an offsetting reduction in $\lambda_{t}^{*}$. This fact has important implications for the dynamic effects of exchange rates.

The variational aspects of the equilibrium for the home country are:

$$
\begin{aligned}
& \lambda_{t}=\beta A \lambda_{t+1}, \\
& \lambda_{0}=\beta\left(\lambda_{1}+\mu_{\mathrm{H} 1}\right) / p_{\mathrm{H} 1}, \\
& \lambda_{t} / p_{\mathrm{H} t}=\beta\left(\lambda_{t+1}+\mu_{\mathrm{H} t+1}\right) / p_{\mathrm{H} t+1}, \\
& \lambda_{0} e_{0}=\beta\left(\lambda_{1} e_{1} / p_{\mathrm{H} 1}+\mu_{\mathrm{F} 1} / p_{\mathrm{F} 1}\right), \\
& \lambda_{t} e_{t} / p_{\mathrm{H} t}=\beta\left(\lambda_{t+1} e_{t+1} / p_{\mathrm{H} t+1}+\mu_{\mathrm{F} t+1} / p_{\mathrm{F} t+1}\right), \\
& \lambda_{0} / R_{\mathrm{H} 0}=\beta \lambda_{1} / p_{\mathrm{H} 1}, \lambda_{t} / R_{\mathrm{H} t} p_{\mathrm{H} t}=\beta \lambda_{t+1} / p_{\mathrm{H} t+1}, \\
& \lambda_{0} e_{0} / R_{\mathrm{F} 0}=\beta \lambda_{1} e_{1} / p_{\mathrm{H} 1}, \\
& \lambda_{t} e_{t} / R_{\mathrm{F} t} p_{\mathrm{H} t}=\beta \lambda_{t+1} e_{t+1} / p_{\mathrm{H} t+1}
\end{aligned}
$$


where $\lambda_{0}$ is the shadow value of Eq. (1). For the sake of brevity, the rules that follow from the solution to the foreign country's maximization are omitted. They involve terms like $1 / e_{t}, 1 / e_{t} p_{\mathrm{Ft}}$ and $\mu_{\mathrm{H} t}^{*} / p_{\mathrm{H} t}$, but are otherwise exactly analogous.

The transversality conditions are:

$$
\begin{aligned}
& \lim _{t \rightarrow \infty} \beta^{t} \lambda_{t} k_{t+1}=\lim _{t \rightarrow \infty} \beta^{t} \lambda_{t}^{*} k_{t+1}^{*}=0, \\
& \lim _{t \rightarrow \infty} \beta^{t} \lambda_{t}\left(M_{\mathrm{H} t+1} / p_{\mathrm{H} t}\right)=\lim _{t \rightarrow \infty} \beta^{t} \lambda_{t}^{*}\left(M_{\mathrm{H} t+1}^{*} / e_{t} p_{\mathrm{F} t}\right)=0, \\
& \lim _{t \rightarrow \infty} \beta^{t} \lambda_{t}\left(e_{t} M_{\mathrm{F} t+1} / p_{\mathrm{H} t}\right)=\lim _{t \rightarrow \infty} \beta^{t} \lambda_{t}^{*}\left(M_{\mathrm{F} t+1}^{*} / p_{\mathrm{F} t}\right)=0, \\
& \lim _{t \rightarrow \infty} \beta^{t} \lambda_{t}\left(B_{\mathrm{H} t+1} / R_{\mathrm{H} t} p_{\mathrm{H} t}\right)=\lim _{t \rightarrow \infty} \beta^{t} \lambda_{t}^{*}\left(B_{\mathrm{H} t+1}^{*} / R_{\mathrm{H} t} e_{t} p_{\mathrm{F} t}\right)=0, \\
& \lim _{t \rightarrow \infty} \beta^{t} \lambda_{t}\left(e_{t} B_{\mathrm{F} t+1} / R_{\mathrm{F} t} p_{\mathrm{H} t}\right)=\lim _{t \rightarrow \infty} \beta^{t} \lambda_{t}^{*}\left(B_{\mathrm{F} t+1}^{*} / R_{\mathrm{Ft}} p_{\mathrm{F} t}\right)=0 .
\end{aligned}
$$

The conditions pertaining to the capital stocks will prove especially useful in simulating the behavior of this economy.

An immediate implication of Eqs. (8) and (9) is that uncovered interest parity holds: $e_{t+1} / e_{t}=R_{\mathrm{H} t} / R_{\mathrm{F} t}$. Also, Eqs. (5) and (8), and their foreign analogs imply that the two Fisher relations have the simple forms:

$$
A=\frac{R_{\mathrm{H} t}}{P_{\mathrm{H} t+1} / P_{\mathrm{H} t}}
$$

and

$$
A=\frac{R_{\mathrm{F} t}}{P_{\mathrm{F} t+1} / P_{\mathrm{F} t}} .
$$

Since the two countries share a common technology, the real interest rates are identical. Hence the real exchange rate is constant, and $\rho_{t}=e_{0} P_{\mathrm{F} 1} / P_{\mathrm{H} 1} \equiv \rho_{0}$ for all $t$. In a regime of fixed exchange rates, the two countries' nominal interest rates and inflation rates are tied together. Otherwise, the rate of depreciation of the nominal exchange rate reflects both the interest and inflation differentials.

Conditions (6) and (8) imply that $R_{\mathrm{H} t-1} \lambda_{t}=\lambda_{t}+\mu_{\mathrm{H} t}$, and Eqs. (7) and (9) imply that $R_{\mathrm{Ft}-1} \lambda_{t}=\lambda_{t}+\mu_{\mathrm{F} t} / \rho_{t}$. The analogs for the foreign country are $R_{\mathrm{H} t-1} \lambda_{t}^{*}=\lambda_{t}^{*}+\rho_{t} \mu_{\mathrm{H} t}^{*}$ and $R_{\mathrm{F} t-1} \lambda_{t}^{*}=\lambda_{t}^{*}+\mu_{\mathrm{F} t}^{*}$. These formulae allow a simple characterization of the decision to purchase credit goods. The home country uses domestic credit for goods $i \in\left[0, j_{\mathrm{H} t}\right]$ and trade credit for imports $i \in\left[0, j_{\mathrm{F} t}\right]$. Otherwise the domestic economy uses home money to buy $i \in\left(j_{\mathrm{H} t}, 1\right]$ and foreign exchange to import $i \in\left(j_{\mathrm{F} t}, 1\right]$.

These two indices are functions respectively of $\left(\lambda_{t}, R_{\mathrm{H} t-1}\right)$ and $\left(\lambda_{t} \rho_{t}, R_{\mathrm{F} t-1}\right)$. To see this, let $\varphi_{\mathrm{H}}\left(\lambda_{t}, R_{\mathrm{H} t-1}\right) \equiv\left[\left(u\left(\tilde{c}_{\mathrm{H} t}\right)-u\left(\hat{c}_{\mathrm{H} t}\right)\right] / \lambda_{t}-\left[\tilde{c}_{\mathrm{H} t}-R_{\mathrm{H} t-1} \hat{c}_{\mathrm{H} t}\right]^{7}\right.$

\footnotetext{
${ }^{7}$ The concavity of $u(\cdot)$ implies that $\varphi_{\mathrm{H}}\left(\lambda_{t}, R_{\mathrm{H} t-1}\right)$ is positive. This fact is also true for its analogs.
} 
The first rule is

$$
j_{\mathrm{H} t}\left(\lambda_{t}, R_{\mathrm{H} t-1}\right)= \begin{cases}1 & \text { if } \varphi_{\mathrm{H}}\left(\lambda_{t}, R_{\mathrm{H} t-1}\right)>\gamma_{\mathrm{H}}(1), \\ \gamma_{\mathrm{H}}^{-1}\left(\varphi_{\mathrm{H}}\left(\lambda_{t}, R_{\mathrm{H} t-1}\right)\right) & \text { if } \varphi_{\mathrm{H}}\left(\lambda_{t}, R_{\mathrm{H} t-1}\right) \in\left[\gamma_{\mathrm{H}}(0), \gamma_{\mathrm{H}}(1)\right], \\ 0 & \text { otherwise. }\end{cases}
$$

Now let $\varphi_{\mathrm{F}}\left(\lambda_{t} \rho_{t}, R_{\mathrm{F} t-1}\right) \equiv\left[\left(u\left(\tilde{c}_{\mathrm{F} t}\right)-u\left(\hat{c}_{\mathrm{F} t}\right)\right] / \lambda_{t} \rho_{t}-\left[\tilde{c}_{\mathrm{F} t}-R_{\mathrm{F} t-1} \hat{c}_{\mathrm{F} t}\right]\right.$. Then the rule for purchasing foreign goods is

$$
j_{\mathrm{F} t}\left(\lambda_{t} \rho_{t}, R_{\mathrm{F} t-1}\right)= \begin{cases}1 & \text { if } \varphi_{\mathrm{F}}\left(\lambda_{t} \rho_{t}, R_{\mathrm{F} t-1}\right)>\gamma_{\mathrm{F}}(1), \\ \gamma_{\mathrm{F}}^{-1}\left(\varphi_{\mathrm{H}}\left(\lambda_{t}, \rho_{t}, R_{\mathrm{F} t-1}\right)\right) & \text { if } \varphi_{\mathrm{F}}\left(\lambda_{t} \rho_{t}, R_{\mathrm{F} t-1}\right) \in\left[\gamma_{\mathrm{F}}(0), \gamma_{\mathrm{H}}(1)\right], \\ 0 & \text { otherwise. }\end{cases}
$$

The Appendix shows that a depreciation of the real exchange rate reduces the measure of imports bought on credit. A real depreciation raises the fixed cost of trade credit and thus reduces imports of these services. Since $\mu_{\mathrm{F} t} / \rho_{t}$ is the shadow value of foreign exchange, a depreciation likewise lowers the opportunity cost of foreign money and increases the share of imports bought with foreign exchange. The rules for the foreign country are analogous, but a real depreciation causes foreigners to purchase a wider array of domestic exports on credit. Thus a real depreciation curtails foreign credit and expands the share of domestic resources used by local financial intermediaries.

It is convenient to define $\widetilde{C}_{\mathrm{H} t} \equiv \int_{0}^{1} \chi_{\mathrm{H} t}(i) \mathcal{C}_{\mathrm{H} t}(i) \mathrm{d} i, \Gamma_{\mathrm{H} t} \equiv \int_{0}^{1} \chi_{\mathrm{H} t}(i) \gamma_{\mathrm{H}}(i) \mathrm{d} i$, and $\widehat{C}_{\mathrm{H} t} \equiv \int_{0}^{1}\left[1-\chi_{\mathrm{H} t}(i)\right] c_{\mathrm{H} t}(i) \mathrm{d} i$. These are the domestic economy's aggregate consumption of home credit goods, domestic credit services, and domestic cash goods. The aggregates $\widetilde{C}_{\mathrm{F} t}, \Gamma_{\mathrm{F} t}$, and $\hat{C}_{\mathrm{F} t}$ are the analogous imports. Further, $\widetilde{C}_{F t}^{*}, \Gamma_{F t}^{*}, \hat{C}_{F t}^{*}, \widetilde{C}_{H t}^{*}, \Gamma_{H t}^{*}$, are the analogs for the foreign country. The Appendix shows that

$$
\begin{aligned}
& \sum_{t=1}^{\infty}\left[\delta_{\mathrm{H} t-1} \rho_{\mathrm{H} t} \hat{C}_{\mathrm{H} t}+\delta_{\mathrm{H} t} p_{\mathrm{H} t}\left(\tilde{C}_{\mathrm{H} t}+\Gamma_{\mathrm{H} t}\right)\right]+e_{0} \sum_{t=1}^{\infty}\left[\delta_{\mathrm{F} t-1} p_{\mathrm{F} t} \hat{C}_{\mathrm{F} t}\right. \\
& \left.+\delta_{\mathrm{F} t} p_{\mathrm{F} t}\left(\tilde{C}_{\mathrm{F} t}+\Gamma_{\mathrm{F} t}\right)\right] \leq k_{0}+\sum_{t=0}^{\infty} \delta_{\mathrm{H} t} H_{t}
\end{aligned}
$$

where $k_{0} \equiv p_{\mathrm{H} 1} A k_{1} / R_{\mathrm{H} 0}$. Likewise the foreign country's choices satisfy

$$
\begin{gathered}
\sum_{t=1}^{\infty}\left[\delta_{\mathrm{H} t-1} p_{\mathrm{H} t} \hat{C}_{\mathrm{H} t}^{*}+\delta_{\mathrm{H} t} p_{\mathrm{H} t}\left(\tilde{C}_{\mathrm{H} t}^{*}+\Gamma_{\mathrm{H} t}^{*}\right)\right]+e_{0} \sum_{t=1}^{\infty}\left[\delta_{\mathrm{F} t-1} p_{\mathrm{F} t} \hat{C}_{\mathrm{F} t}^{*}\right. \\
\left.+\delta_{\mathrm{F} t} p_{\mathrm{F} t}\left(\tilde{C}_{\mathrm{F} t}^{*}+\Gamma_{\mathrm{F} t}^{*}\right)\right] \leq k_{0}^{*}+e_{0} \sum_{t=0}^{\infty} \delta_{\mathrm{F} t} H_{t}^{*}
\end{gathered}
$$

where now $k_{0}^{*} \equiv e_{0} p_{\mathrm{F} 1} k_{1} / R_{\mathrm{F} 0}$. These constraints discount credit goods by one extra period, showing precisely how cash goods are more expensive than credit 
goods. They also demonstrate that each country's wealth depends upon its money supply process and the initial nominal exchange rate. This exchange rate determines a country's well-being since it affects both countries' monetary policies and the pattern of trade.

Since the real exchange rate is constant, it will have an effect on a country's long-run growth only if it influences the asymptotic share of national income spent on foreign credit. Thus the long-run effect of exchange rates will depend upon the nature of $\lim _{t \rightarrow \infty} \Gamma_{\mathrm{F} t} / k_{t+1}$, and little can be said about this term unless explicit assumptions about the costs of trade credit are made.

The real exchange rate, however, can have an important effect during the early stage of development. The terms $\widetilde{C}_{\mathrm{H} t}, \Gamma_{\mathrm{H} t}$ and $\hat{C}_{\mathrm{H} t}$ do not depend upon the real exchange rate, but $\widetilde{C}_{\mathrm{F} t}, \Gamma_{\mathrm{F} t}$ and $\hat{C}_{\mathrm{F} t}$ all do. If $\rho_{0}$ is sufficiently high, then $\Gamma_{\mathrm{F} t}=\tilde{C}_{\mathrm{F} t}=0$ for finitely many $t$. Also, a country's demand for foreign cash goods depends negatively upon the real exchange rate and the foreign nominal interest rate.

There is an intermediate stage during which the domestic economy becomes integrated into the world financial system. At this point, both $\Gamma_{\mathrm{F} t}$ and $\widetilde{C}_{\mathrm{F} t}$ become positive. If foreign nominal interest rates are strictly positive, then the domestic economy will replace a smaller volume of transactions in imported cash goods with a larger volume of foreign credit goods. Thus, during this intermediate stage, growth drops and the external surplus decreases.

\section{A parametric example}

Of course, the exact description of the credit technologies will largely determine the properties of the equilibrium of the world economy. I assume that $\gamma_{\mathrm{H}}(i)=\tan (\pi i / 2)$ and $\gamma_{\mathrm{F}}(i)=F+\tan (\pi i / 2)$, where $F>0$ is the fixed cost of finding foreign credit in a neighborhood of the foreign financial center. I also impose symmetric credit costs: $\gamma_{\mathrm{H}}^{*}(i)=\gamma_{\mathrm{F}}(i)$ and $\gamma_{\mathrm{F}}^{*}(i)=\gamma_{\mathrm{H}}(i)$. This symmetry shows that neither country has a comparative advantage in verifying international creditworthiness. Also, these functions have easy inverses, and $\Gamma_{\mathrm{H} t} \equiv \int_{0}^{j_{\mathrm{H}}} \gamma_{\mathrm{H}}(i) \mathrm{d} i=-\ln \left(\cos \left(\pi j_{\mathrm{H} t} / 2\right)\right)$.

Let $u(\cdot)=u^{*}(\cdot)=\ln (\cdot)$ so that the asymptotic growth properties are simple to describe. It follows that $\tilde{c}_{\mathrm{H} t}=1 / \lambda_{t}, \hat{c}_{\mathrm{H} t}=1 / \lambda_{t} R_{\mathrm{H} t-1}, \tilde{c}_{\mathrm{F} t}=1 / \rho_{t} \lambda_{t}$, and $\hat{c}_{\mathrm{F} t}=1 / \rho_{t} \lambda_{t} R_{\mathrm{Ft}-1}$. The relevant values for the foreign country are: $\tilde{c}_{\mathrm{F} t}^{*}=1 / \lambda_{t}^{*}, \hat{c}_{\mathrm{F} t}^{*}=1 / \lambda_{t}^{*} R_{\mathrm{F} t-1}, \tilde{c}_{\mathrm{H} t}^{*}=\rho_{t} / \lambda_{t}^{*}$, and $\hat{c}_{\mathrm{F} t}^{*}=\rho_{t} / \lambda_{t} R_{\mathrm{H} t-1}$. Also, the evolution of the margins between credit and cash goods follows:

$$
\begin{aligned}
& j_{\mathrm{H} t}=\max \left\{0,(2 / \pi) \arctan \left(\ln \left(R_{\mathrm{H} t-1}\right) / \lambda_{t}\right)\right\}, \\
& j_{\mathrm{F} t}=\max \left\{0,(2 / \pi) \arctan \left(-F+\ln \left(R_{\mathrm{F} t-1}\right) / \rho_{t} \lambda_{t}\right)\right\} .
\end{aligned}
$$


Likewise,

$$
\begin{aligned}
j_{\mathrm{F} t}^{*} & =\max \left\{0,(2 / \pi) \arctan \left(\ln \left(R_{\mathrm{F} t-1}\right) / \lambda_{t}^{*}\right)\right\}, \\
j_{\mathrm{H} t}^{*} & =\max \left\{0,(2 / \pi) \arctan \left(-F+\rho_{t} \ln \left(R_{\mathrm{H} t-1}\right) / \lambda_{t}^{*}\right)\right\} .
\end{aligned}
$$

Now consider an equilibrium in which both domestic and foreign nominal interest rates are eventually constant. Then Eq. (5) and the form of the felicity function imply that the long-run growth rate is $A \beta$ if the share of resources used for credit is asymptotically zero. The Appendix shows this is true. Still, the economy's use of resources for financial intermediation is not bounded, although the share of that sector shrinks as the economy grows. In a more general class of equilibria in which strictly positive interest rates display cycles, the cashin-advance constraints would always bind. The long-run growth rates would still approach $A \beta$, although there might be credit cycles depending upon how interest rates affected aggregate demand.

There is no analytical description of the equilibrium, even under the simple assumption that interest rates are constant. The rest of this section describes simulations of equilibria using parameters given in Table 1.

Real interest rates are 3\%, and the long-run growth rate of the world economy satisfies $A \beta=1.0197$, chosen to match Ireland's (1994) simulations based upon King and Rebelo (1990). The initial capital stocks play two roles. First, each country is large, and monetary policy will have both domestic and international effects. Second, the absolute size of an economy determines the initial share of the financial sector. For example, if the economy purchases $28 \%$ of its goods with credit, then about $10 \%$ of GDP is spent on financial intermediaries. $^{8}$ Also, since $F=1$, an economy that purchases $5 \%$ of foreign goods on credit uses almost $5 \%$ of GDP just paying for the services of foreign financiers.

Notice first that social welfare is maximized if each government follows a Friedman rule: set the nominal interest rate at zero and allow each economy to deflate at $1 / A$ so that money is not denominated in rate of return. ${ }^{9}$ In an international economy, this is not quite a complete specification of equilibrium because a planner still can choose how to split consumption between countries in each period. In essence, different initial nominal exchange rates serve this purpose, and Fig. 1 gives the utility frontier for the world economy. ${ }^{10}$ The frontier is linear because the utility functions allow simple aggregation across

\footnotetext{
${ }^{8}$ In the national income and product accounts of the United States, the rubric finance, insurance, and real estate has contributed about $10 \%$ of value added in the last two decades.

${ }^{9}$ Also, the world economy is immediately on its asymptotic growth path.

${ }^{10}$ Imposing the transversality conditions for both capital stocks, I used a shooting algorithm for these and all subsequent simulations. In essence, this algorithm searches for values for $\lambda_{0}$ and $\lambda_{0}^{*}$ and then checks if each country's gross growth rate is $A \beta \pm 0.000001$ after $1000 \mathrm{yr}$.
} 
Table 1

The model parameters

\begin{tabular}{lllll}
\hline$A$ & $\beta$ & $k_{0}$ & $k_{0}^{*}$ & $F$ \\
\hline 1.03 & 0.99 & 1 & 1 & 1 \\
\hline
\end{tabular}

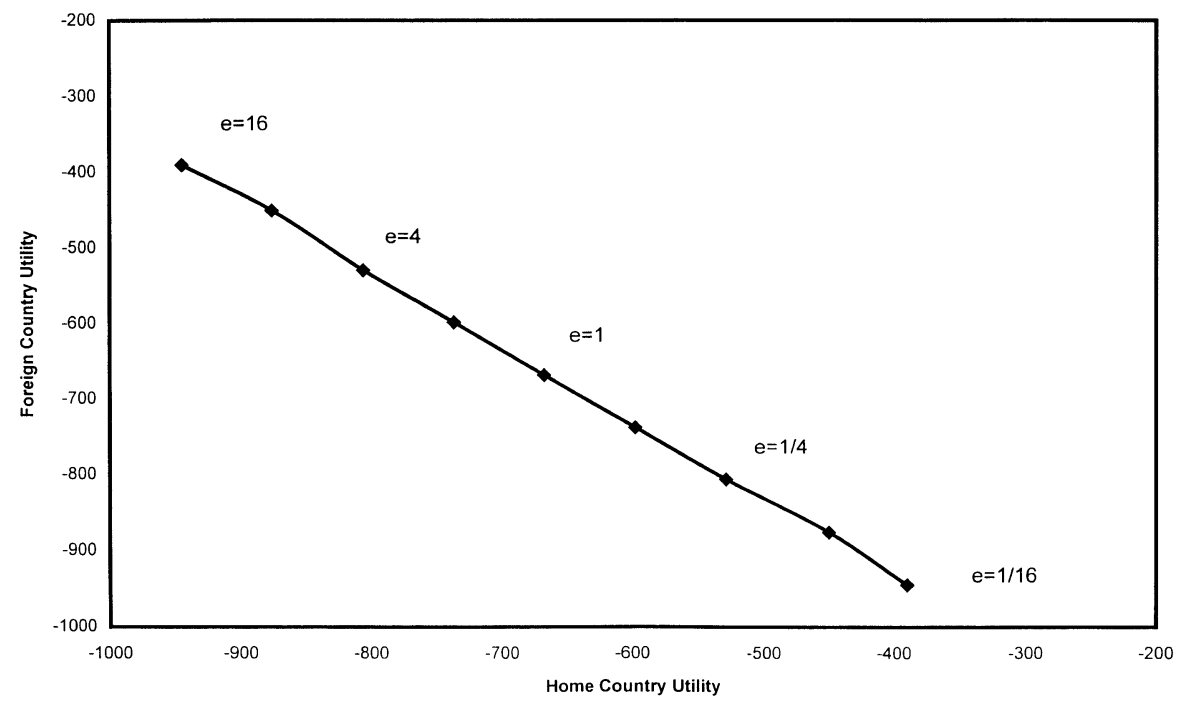

Fig. 1. Pareto frontier.

countries, and we see that a weak exchange rate corresponds to a low level of domestic utility. The natural focal point is of course when $e_{0}=1$ and domestic and foreign utilities are both -668 .

Unfortunately, countries do not follow Friedman rules. Thus I calibrate a base case that simulates the actual world economy more closely. In particular, I set the domestic nominal interest rate at $4 \%$ per annum and the foreign nominal interest rate at $8 \%$; the Fisher relations imply that domestic inflation is $1 \%$ and foreign inflation is $5 \%$. Figs. 2 and 3 are then drawn for $e_{0}=1$.

Fig. 2 shows clearly the three phases that characterize an economy's growth path. First, a country uses foreign exchange to buy foreign goods; thus its export earnings constrain its imports. Second, there is an intermediate period of rapidly expanding use of trade credit, when the growth rate drops as real resources are used to become integrated into the world financial system. Third, a country grows asymptotically at the rate reflecting the effects of the discount factor and 


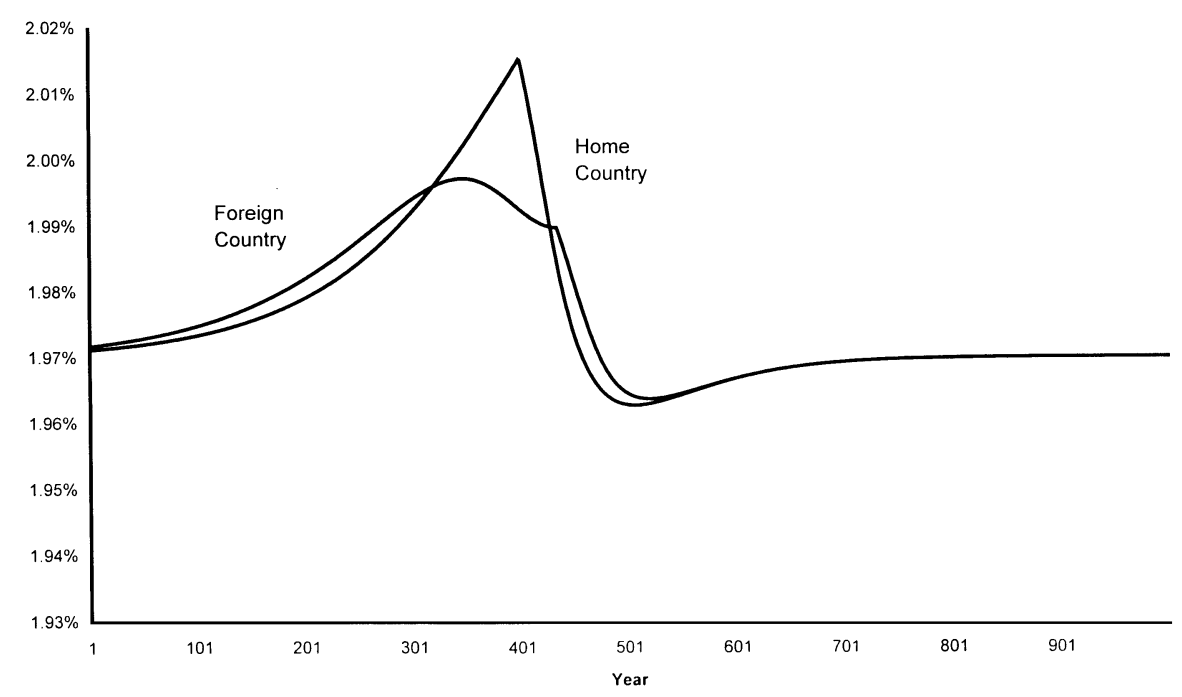

Fig. 2. Base case growth rates.

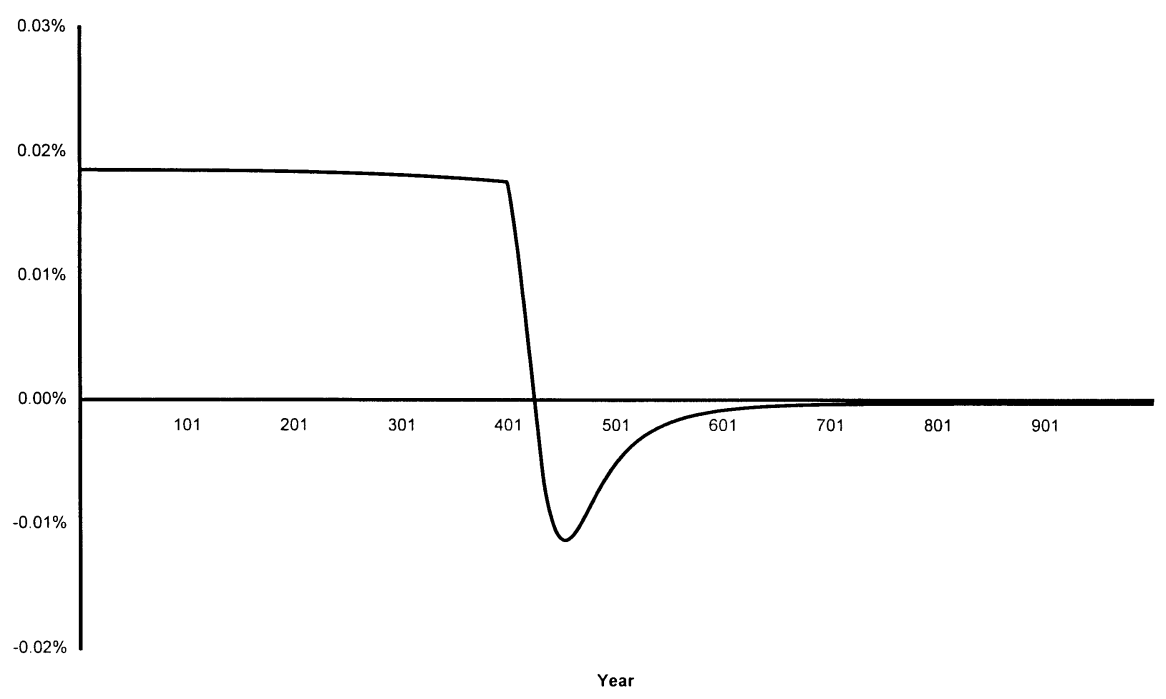

Fig. 3. External balance/GDP.

the marginal efficiency of investment. In the long run, almost all goods are purchased with credit, although there are always small sectors in both countries that use currencies as means of payment. Notice that the high rate of foreign inflation spurs the domestic economy to a higher peak growth rate. These 
moderately positive nominal interest rates entail a slight loss of utility for each country, but the welfare loss for the foreign country is less than $0.1 \%$ and it is even lower for the home country. Thus low inflation rates put both economies only slightly inside the Pareto frontier.

Fig. 3 shows the domestic economy's external balance as a percentage of its gross domestic product. This balance includes the trade surplus and the surplus on financial services. The home country runs initial surpluses because foreigners take advantage of low domestic interest rates to buy a large volume of domestic cash goods. Also, the domestic economy's share of world wealth is less than its share of world population since its rate of monetary expansion is relatively low. It runs an initial external surplus that is eventually exhausted once the home country becomes fully integrated into the international financial system.

Fig. 4 relates exchange rates and growth paths; the domestic and foreign inflation and interest rates are the same as the base case but the initial nominal (and real) exchange rate varies. Since the long-run share of resources used in trade credit does not depend upon the real exchange rate, it can only have a transitory growth effect. A stronger exchange rate is not associated with higher peak growth rates; instead it is related to the speed of integration of the home country into the world financial system. Thus a real appreciation is correlated with increased growth rates during the early phase of an economy's growth trajectory. Also, a stronger exchange rate is linked with lower external balances and higher domestic welfare.

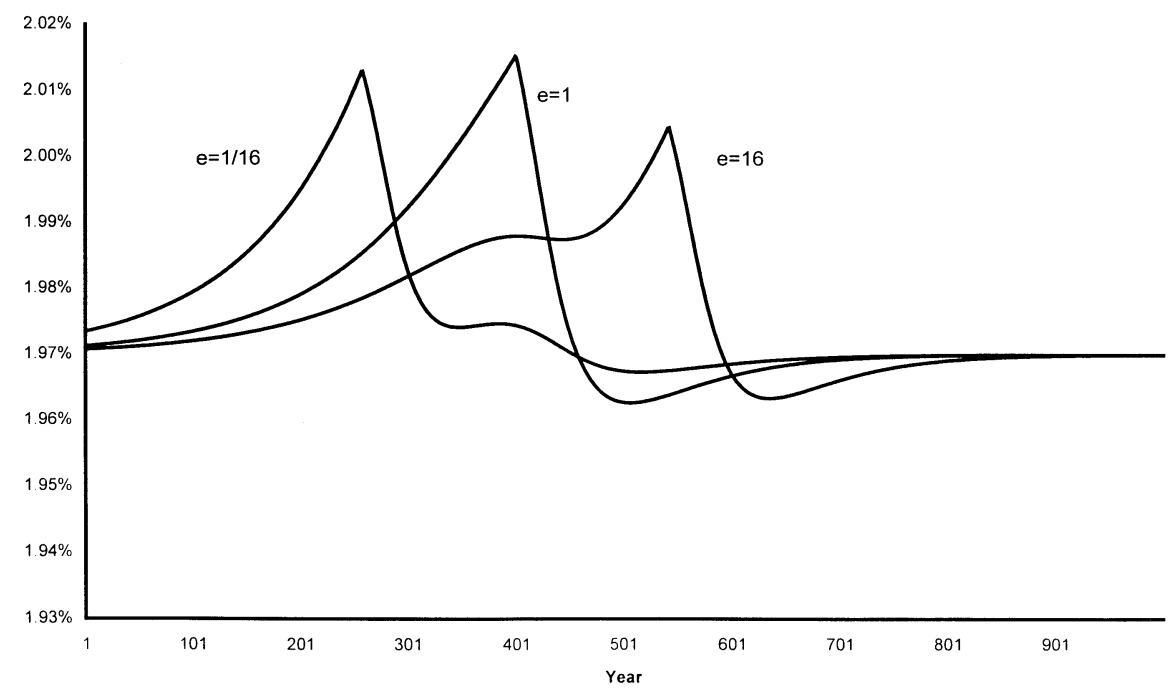

Fig. 4. Exchange rates and growth rates. 
Figs. 5 and 6 show the domestic and international Tobin effects. In Fig. 5, foreign interest rates and the exchange rate are as in the base case, but the domestic interest rate is allowed to vary. Low rates occur when the domestic economy sets the nominal interest rate at zero, and the high rates correspond to

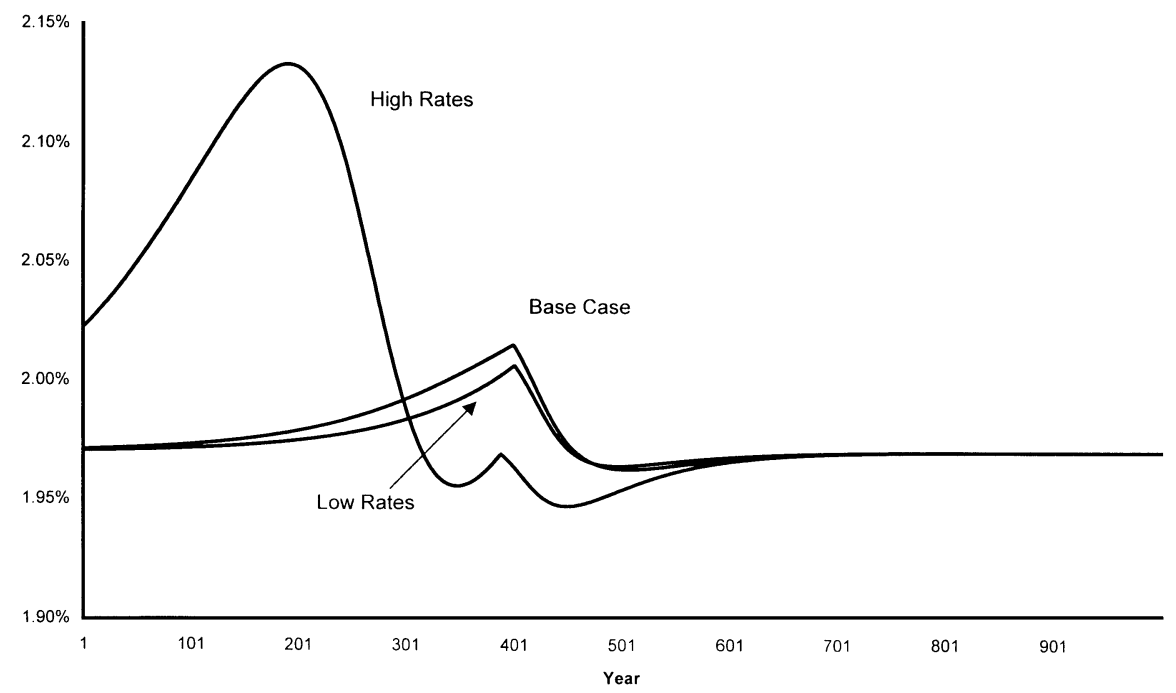

Fig. 5. Domestic growth rates and domestic interest rates.

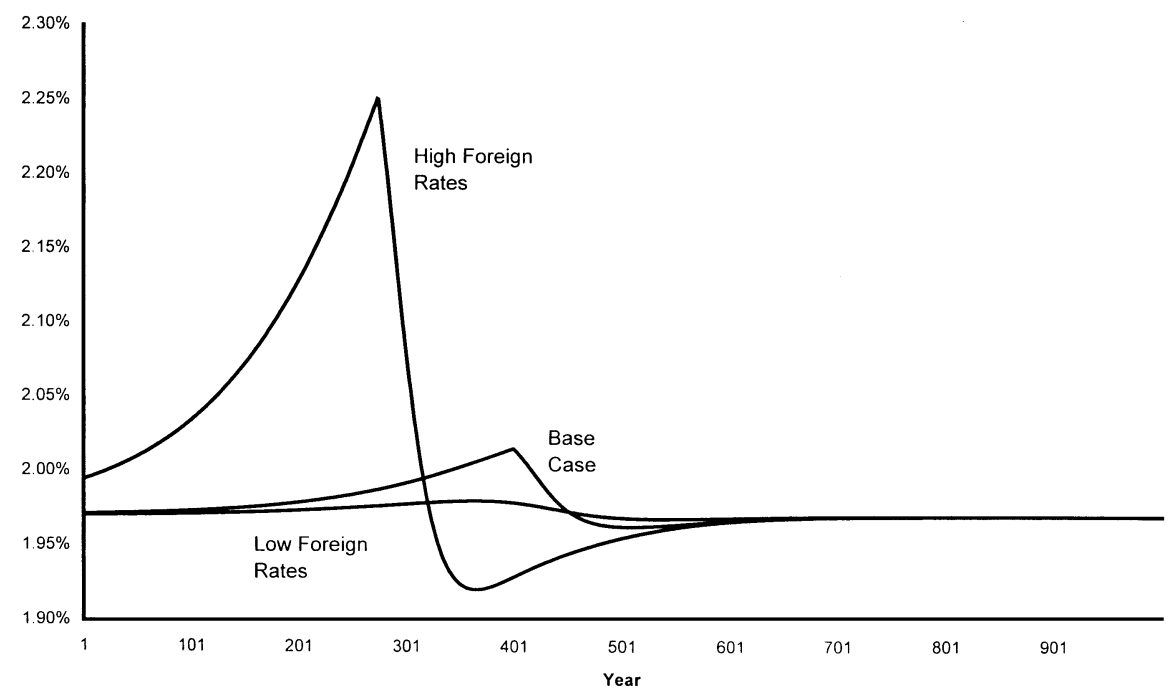

Fig. 6. Domestic growth rates and foreign interest rates. 
a nominal interest rate of $103 \%$ and thus inflation is near $100 \%$ per annum. This diagram simply underscores that Ireland's findings are robust in a two-country world: higher domestic inflation spurs growth in the short run. Fig. 6 is analogous, but now the home interest rate and exchange rate are as in the base case, and foreign interest rates are allowed to be $0 \%, 8 \%$, or $103 \%$. This diagram shows that a country exports its Tobin effect since higher foreign inflation spurs domestic growth as consumers switch from imported cash goods to investment, the quintessential domestic credit good. Notice also that higher foreign rates increase the speed at which the domestic economy becomes integrated into the world financial system. Thus the effects of foreign inflation are twofold: they raise domestic growth and peak growth rates occur earlier.

Fig. 7 is the first example in the literature of an anticipated Tobin effect. In this case, the exchange rate and domestic and foreign interest rates are the same as in the base case for $100 \mathrm{yr}$. Then domestic interest rates increase from $4 \%$ to $6 \%$ per annum. Uncovered interest parity implies an anticipated discrete depreciation of the nominal exchange rate in period 101. Anticipated inflation reduces growth at home and abroad until higher domestic inflation occurs. Then there is a discrete jump in growth when the policy is implemented. For this parameterization of the model, there is a short-run trade-off between inflation and economic activity, although higher growth actually means lower welfare at home and abroad. Further, the anticipated depreciation actually lowers the external

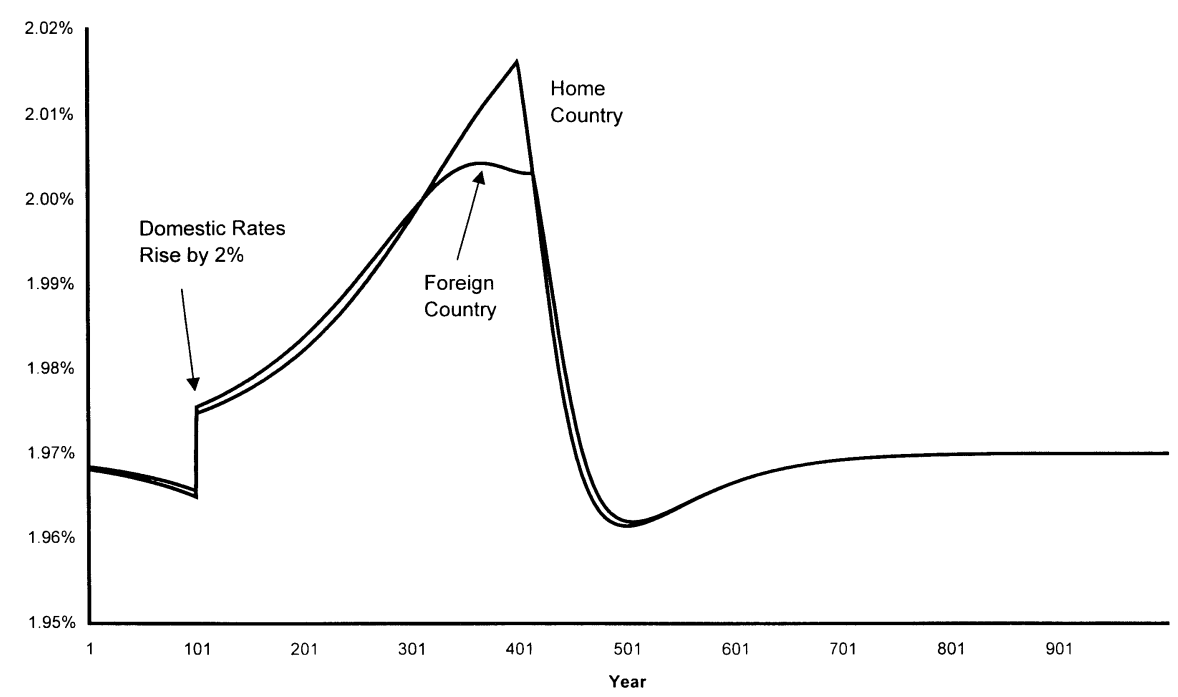

Fig. 7. Anticipated rise in inflation. 
surplus, since higher rates of domestic money creation raise the initial share of world wealth accruing to the home country.

\section{Conclusion}

In an important sense, this model largely confirms Sidrauski's (1967) seminal work. For plausible specifications of the credit technologies, inflation only has transitory growth effects. But the simulations conducted in Section 4 certainly suggest that inflation can have effects that last well beyond the planning horizon of a government in a modern industrial economy. The growth effects of moderate rates of inflation are not large, but high inflation can raise growth significantly, at least for several decades.

Exchange rates are associated with two effects in this model. First, a strong exchange rate is linked with how quickly an economy becomes integrated into the world financial system. Thus a low inflation country with a strong exchange rate has an initial growth spurt and then a decline in growth as it makes the transition from using foreign exchange to foreign financial intermediaries to pay for imports. Second, a real appreciation rate is associated with a larger external deficit. In the simulations presented in Section 4, a real appreciation of $100 \%$ is equivalent to a gain of about $10 \%$ of national output when both countries conduct monetary policies that maximize social welfare.

It is worth emphasizing that there is no prisoner's dilemma for monetary policy here. Each country finds it in its own self-interest to set its nominal interest rate at zero, and a regime of fixed exchange rates emerges naturally in this framework. Of course, the key issue is: what fixed exchange would the two central banks support? The natural focal point is related to the two countries relative shares in world wealth, but in the end, there is no strong philosophical argument for any particular exchange rate, especially when the gains from trade are high. ${ }^{11}$ Thus describing the details of a monetary union perhaps falls more in the realm of political science than of economics.

This paper is only the first step in what may become a larger literature. There have been so few applied theoretical analyses of exchange rates and economic growth because there is a genuine paucity of satisfying models in which money plays an explicit role. This paper has imposed a cash-in-advance constraint, but there are other approaches with their own strengths and weaknesses. Different perspectives on monetary phenomena in growing economies will shed further light on the relationship between exchange rates and growth. Still, the link between trade credit and growth seems important, and measuring the strength of this relationship is a ripe area for empirical research.

${ }^{11}$ This is implicit in the arguments in Fisher (1996), where countries are modeled as sequences of agents. 


\section{Acknowledgements}

The author will make available a diskette with all the Gauss programs used to simulate the economies described above. He would like to thank an anonymous referee, Mario Crucini, Paul Evans, Peter Howitt, Peter Ireland, Bill Dupour, and seminar participants at The Ohio State University and the University at Buffalo for comments on earlier drafts.

\section{Appendix}

Claim A.1. If foreign interest rates are strictly positive, then a depreciation of the real exchange rate reduces the measure of foreign goods bought on credit.

Proof. Total differentiation of the equality

$$
u\left(\tilde{c}_{\mathrm{F} t}\right)-\lambda_{t} \rho_{t}\left(\tilde{c}_{\mathrm{F} t}+\gamma_{\mathrm{F}}(i)\right)=u\left(\hat{c}_{\mathrm{F} t}\right)-\left(\lambda_{t} \rho_{t}+\mu_{\mathrm{F} t}\right) \hat{c}_{\mathrm{F} t}
$$

yields

$$
\begin{gathered}
u^{\prime}\left(\tilde{c}_{\mathrm{F} t}\right) \partial \tilde{c}_{\mathrm{F} t} / \partial \rho_{t}-\lambda_{t} \tilde{c}_{\mathrm{F} t}-\lambda_{t} \gamma_{\mathrm{F}}(i)-\lambda_{t} \rho_{t} \partial \tilde{c}_{\mathrm{F} t} / \partial \rho_{t}-\lambda_{t} \rho_{t} \gamma_{\mathrm{F}}^{\prime}(i) \partial i / \partial \rho_{t} \\
=u^{\prime}\left(\hat{c}_{\mathrm{F} t}\right) \partial \hat{c}_{\mathrm{F} t} / \partial \rho_{t}-\lambda_{t} \hat{c}_{\mathrm{F} t}-\left(\lambda_{t} \rho_{t}+\mu_{\mathrm{F} t}\right) \partial \hat{c}_{\mathrm{F} t} / \partial \rho_{t} .
\end{gathered}
$$

But $u^{\prime}\left(\tilde{c}_{\mathrm{F} t}\right)=\lambda_{t} \rho_{t}$ and $u^{\prime}\left(\hat{c}_{\mathrm{F} t}\right)=\lambda_{t} \rho_{t}+\mu_{\mathrm{F} t}$. Thus $\rho_{t} \gamma_{\mathrm{F}}^{\prime}(i) \partial i / \partial \rho_{t}=\hat{c}_{\mathrm{F} t}-\tilde{c}_{\mathrm{F} t}-\gamma_{\mathrm{F}}(i)$. Since $\hat{c}_{\mathrm{F} t}<\tilde{c}_{\mathrm{F} t}, \gamma_{\mathrm{F}}(i)>0$, and $\gamma_{\mathrm{F}}^{\prime}(i)>0$, we may conclude that $\partial i / \partial \rho_{t}=$ $\left[\hat{c}_{\mathrm{F} t}-\tilde{c}_{\mathrm{F} t}-\gamma_{\mathrm{F}}(i)\right] / \rho_{t} \gamma_{\mathrm{F}}^{\prime}(i)$. This completes the proof.

Claim A.2. There are simple expressions for the countries' budget constraints.

Proof. Using the notation in the text, we can define domestic and foreign money-to-hold and see that $m_{\mathrm{H} t} \equiv M_{\mathrm{H} t}-p_{\mathrm{H} t} \hat{C}_{\mathrm{H} t} \geq 0$ and $m_{\mathrm{F} t} \equiv$ $M_{\mathrm{F} t}-p_{\mathrm{F} t} \hat{C}_{\mathrm{F} t} \geq 0$. Then Eq. (1) implies:

$$
p_{\mathrm{H} 1} \hat{C}_{\mathrm{H} 1}+m_{\mathrm{H} 1}+B_{\mathrm{H} 1} / R_{\mathrm{H} 0}+e_{0} p_{\mathrm{F} 1} \hat{C}_{\mathrm{F} 1}+e_{0} m_{\mathrm{F} 1}+e_{0} B_{\mathrm{F} 1} / R_{F 0} \leq H_{0} .
$$

Also, the budget constraint for $t=1$ implies:

$$
\begin{aligned}
& p_{\mathrm{H} 1} k_{2}+p_{\mathrm{H} 1}\left(\tilde{C}_{\mathrm{H} 1}+\Gamma_{\mathrm{H} 1}\right)+M_{\mathrm{H} 2}+B_{\mathrm{H} 2} / R_{\mathrm{H} 1}+e_{1} p_{\mathrm{F} 1}\left(\tilde{C}_{\mathrm{F} 1}+\Gamma_{\mathrm{F} 1}\right) \\
& \quad+e_{1} B_{\mathrm{F} 2} / R_{\mathrm{F} 1}+e_{1} M_{\mathrm{F} 2} \leq p_{\mathrm{H} 1} A k_{1}+B_{\mathrm{H} 1}+m_{\mathrm{H} 1}+e_{1} m_{\mathrm{F} 1}+e_{1} B_{\mathrm{F} 1}+H_{1} .
\end{aligned}
$$

Divide this expression by $R_{\mathrm{H} 0}$, add it to the previous one, and use $e_{1} / e_{0}=R_{\mathrm{H} 0} / R_{\mathrm{F} 0}$ to derive:

$$
\begin{aligned}
& p_{\mathrm{H} 1} \hat{C}_{\mathrm{H} 1}+e_{0} p_{\mathrm{F} 1} \hat{C}_{\mathrm{F} 1}+p_{\mathrm{H} 1}\left(\tilde{C}_{\mathrm{H} 1}+\Gamma_{\mathrm{H} 1}\right) / R_{\mathrm{H} 0}+e_{0} p_{\mathrm{F} 1}\left(\widetilde{C}_{\mathrm{F} 1}+\Gamma_{\mathrm{F} 1}\right) / R_{\mathrm{F} 0} \\
& +m_{\mathrm{H} 1}\left(R_{\mathrm{H} 0}-1\right) / R_{\mathrm{H} 0}+e_{0} m_{\mathrm{F} 1}\left(R_{\mathrm{F} 0}-1\right) / R_{\mathrm{F} 0}+M_{\mathrm{H} 2} / R_{\mathrm{H} 0}
\end{aligned}
$$




$$
\begin{aligned}
& +B_{\mathrm{H} 2} / R_{\mathrm{H} 1} R_{\mathrm{H} 0}+e_{0} B_{\mathrm{F} 2} / R_{\mathrm{F} 1} R_{\mathrm{F} 0}+e_{0} M_{\mathrm{F} 2} / R_{\mathrm{F} 0}+p_{\mathrm{H} 1} k_{2} / R_{\mathrm{H} 0} \\
& \leq p_{\mathrm{H} 1} A k_{1} / R_{\mathrm{H} 0}+H_{0}+H_{1} / R_{\mathrm{H} 0} .
\end{aligned}
$$

But $m_{\mathrm{H} 1}\left(R_{\mathrm{H} 0}-1\right) / R_{\mathrm{H} 0}=e_{0} m_{\mathrm{F} 1}\left(R_{\mathrm{F} 0}-1\right) / R_{\mathrm{F} 0}=0$ because the interest rate is strictly positive if and only if the relevant cash-in-advance constraint binds. Thus we may write

$$
\begin{aligned}
& p_{\mathrm{H} 1} \hat{C}_{\mathrm{H} 1}+e_{0} p_{\mathrm{F} 1} \hat{C}_{\mathrm{F} 1}+p_{\mathrm{H} 1}\left(\tilde{C}_{\mathrm{H} 1}+\Gamma_{\mathrm{H} 1}\right) / R_{\mathrm{H} 0}+e_{0} p_{\mathrm{F} 1}\left(\tilde{C}_{\mathrm{F} 1}+\Gamma_{\mathrm{F} 1}\right) / R_{\mathrm{F} 0} \\
& +M_{\mathrm{H} 2} / R_{\mathrm{H} 0}+B_{\mathrm{H} 2} / R_{\mathrm{H} 1} R_{\mathrm{H} 0}+e_{0} B_{\mathrm{F} 2} / R_{\mathrm{F} 1} R_{\mathrm{F} 0}+e_{0} M_{\mathrm{F} 2} / R_{\mathrm{F} 0} \\
& +p_{\mathrm{H} 1} k_{2} / R_{\mathrm{H} 0} \leq k_{\mathrm{H} 0}+H_{0}+H_{1} / R_{\mathrm{H} 0}
\end{aligned}
$$

where $k_{\mathrm{H} 0} \equiv p_{\mathrm{H} 1} A k_{1} / R_{\mathrm{H} 0}$. Repeating these two steps of algebra for $t \geq 1$, we derive

$$
\begin{aligned}
& \sum_{s=1}^{t}\left[\delta_{\mathrm{H} s-1} p_{\mathrm{H} s} \hat{C}_{\mathrm{Hs}}+\delta_{\mathrm{H} s} p_{\mathrm{Hs}}\left(\tilde{C}_{\mathrm{H} s}+\Gamma_{\mathrm{H} s}\right)\right]+\delta_{\mathrm{H} t} M_{\mathrm{H} t+1}+\delta_{\mathrm{H} t+1} B_{\mathrm{H} t+1} \\
& +\delta_{\mathrm{H} t} p_{\mathrm{H} t} k_{t+1}+e_{0} \sum_{s=1}^{t}\left[\delta_{\mathrm{Fs}-1} p_{\mathrm{Fs}} \hat{C}_{\mathrm{F} s}+\delta_{\mathrm{Fs}} p_{\mathrm{Fs}}\left(\hat{C}_{\mathrm{Fs}}+\Gamma_{\mathrm{Fs}}\right)\right] \\
& \quad+e_{0} \delta_{\mathrm{F} t} M_{\mathrm{F} t+1}+e_{0} \delta_{\mathrm{F} t+1} B_{\mathrm{F} t+1} \leq k_{\mathrm{H} 0}+\sum_{s=0}^{t} \delta_{s} H_{s}
\end{aligned}
$$

where the discount factors are as in the text. The first-order conditions imply that $R_{\mathrm{H} t} p_{\mathrm{H} t}=A p_{\mathrm{H} t+1}$, and I have used this relation to eliminate the terms $p_{\mathrm{H} t} k_{\mathrm{H} t+1}$ and $p_{\mathrm{H} t+1} A k_{t+1} / R_{\mathrm{H} t}$. Now the asymptotic constraints on the domestic and foreign bond markets imply that $\lim _{t \rightarrow \infty} \delta_{\mathrm{H} t+1} B_{\mathrm{H} t+1}=\lim _{t \rightarrow \infty} \delta_{\mathrm{F} t+1} B_{\mathrm{F} t+1}=0$. Also, the transversality conditions imply $\lim _{t \rightarrow \infty} \delta_{\mathrm{H} t} M_{\mathrm{H} t+1}=\lim _{t \rightarrow \infty} \delta_{\mathrm{Ft}} M_{\mathrm{F} t+1}=$ $\lim _{t \rightarrow \infty} \delta_{\mathrm{H} t} p_{\mathrm{H} t} k_{\mathrm{H} t+1}=0$. Thus

$$
\begin{aligned}
& \sum_{s=1}^{\infty}\left[\delta_{\mathrm{H} s-1} p_{\mathrm{Hs}} \hat{C}_{\mathrm{H} s}+\delta_{\mathrm{Hs}} p_{\mathrm{Hs}}\left(\tilde{C}_{\mathrm{H} s}+\Gamma_{\mathrm{Hs}}\right)\right]+e_{0} \sum_{s=1}^{\infty}\left[\delta_{\mathrm{Fs}-1} p_{\mathrm{Fs}} \hat{C}_{\mathrm{Fs}}\right. \\
& \left.\quad+\delta_{\mathrm{Fs}} p_{\mathrm{Fs}}\left(\tilde{C}_{\mathrm{Fs}}+\Gamma_{\mathrm{Fs} s}\right)\right] \leq k_{\mathrm{H} 0}+\sum_{s=0}^{\infty} \delta_{s} H_{s}
\end{aligned}
$$

where I have imposed that the present value of the monetary transfers be well defined. The analogous condition holds for the foreign country. This completes the proof.

Claim A.3. For the example in Section 4, the asymptotic share of resources used in financial intermediation is zero. 
Proof. Working in continuous time and using L'Hôpital's rule, I will show that $\lim _{t \rightarrow \infty} \Gamma_{\mathrm{H} t} / A k_{t}=0$. Since $\pi j_{\mathrm{H} t} / 2=\arctan \left(\ln R_{\mathrm{H} t-1} / \lambda_{t}\right)$, it is natural to define

$$
\varphi(t)=\frac{-\ln (\cos \theta(t))}{A k_{0} \mathrm{e}^{g t}},
$$

where $\theta(t)=\arctan \left(\ln R_{\mathrm{H} t-1} / \lambda_{t}\right)$ and $g=A \beta$. Then the continuous time analog of first-order conditions implies $R_{\mathrm{H} t-1} / \lambda_{t}=R_{\mathrm{H} 0} \mathrm{e}^{g t} / \lambda_{0}$ for a fixed path of interest rates. Now

$$
\begin{aligned}
\lim _{t \rightarrow \infty} \varphi(t) & =\lim _{t \rightarrow \infty} \frac{(\tan \theta(t)) \theta^{\prime}(t)}{A k_{0} g \mathrm{e}^{g t}}=\lim _{t \rightarrow \infty} \frac{\left(\ln R_{\mathrm{H} 0}\right) \mathrm{e}^{g t} \theta^{\prime}(t)}{\lambda_{0} A k_{0} g \mathrm{e}^{g t}} \\
& =\lim _{t \rightarrow \infty} \frac{\left(\ln R_{\mathrm{H} 0}\right) \theta^{\prime}(t)}{\lambda_{0} A k_{0} g}
\end{aligned}
$$

where I have used that the derivative of $-\ln (\cos \theta)$ is $\tan \theta$. The derivative of $\arctan (x)$ is $1 /\left(1+x^{2}\right)$. Hence,

$$
\begin{aligned}
\lim _{t \rightarrow \infty} \frac{\left(\ln R_{\mathrm{H} 0}\right) \theta^{\prime}(t)}{\lambda_{0} A k_{0} g} & =\lim _{t \rightarrow \infty} \frac{\left(\ln R_{\mathrm{H} 0}\right) g \mathrm{e}^{g t} / \lambda_{0}}{\lambda_{0} A k_{0} g\left\{1+\left[\left(\ln R_{\mathrm{H} 0}\right) \mathrm{e}^{g t} / \lambda_{0}\right]^{2}\right\}} \\
& =\lim _{t \rightarrow \infty} \frac{\ln R_{\mathrm{H} 0}}{A k_{0}\left(\lambda_{0}^{2} \mathrm{e}^{-g t}+\left(\ln R_{\mathrm{H} 0}\right)^{2} \mathrm{e}^{g t}\right)}=0 .
\end{aligned}
$$

The analog for foreign financial intermediation is immediate since the real exchange rate is constant. This completes the proof.

\section{References}

Becker, R.A., 1980. On the long-run steady state in a simple dynamic model of equilibrium with heterogeneous households. Quarterly Journal of Economics 95, 375-382.

Dupour, B., 1997. Exchange Rates and the Fiscal Theory of the Price Level. University of Pennsylvania, Unpublished manuscript.

Fisher, E.O'N., 1996. On Exchange Rates and Efficiency. Economic Theory 7, 267-281.

Helpman, E., 1981. An exploration in the theory of exchange-rate regimes. Journal of Political Economy 89, 865-890.

Ireland, P.N., 1994. Money and growth: an alternative approach. American Economic Review 84, 47-65.

Jones, L.E., Manuelli, R.E., 1997. The sources of growth. Journal of Economic Dynamics and Control 21, 75-114.

King, R.G., Rebelo, S., 1990. Public policy and economic growth: developing neoclassical implications. Journal of Political Economy 98, S126-50.

Kohn, M., 1981. In defense of the finance constraint. Economic Inquiry 19, 177-195.

Lucas, R.E. Jr., Stokey, N.L., 1987. Money and interest in a cash-in-advance economy. Econometrica $55,491-514$. 
Prescott, E.C., 1987. A multiple means-of-payment model. In: Barnett, W.A., Singleton, K.J. (Eds.), New Approaches to Monetary Economics. Cambridge University Press, Cambridge.

Schreft, S.L., 1992. Transactions costs and the use of cash and credit. Economic Theory 2, 283-296.

Sidrauski, M., 1967. Rational choice and patterns of growth in a monetary economy. American Economic Review Papers and Proceedings 57, 534-544.

Tobin, J., 1965. Money and economic growth. Econometrica 33, 671-684. 